\title{
Estado nacional y poderes provinciales. Aspectos del sistema político peruano antes de la Guerra con Chile*
}

\author{
Ulrich Mücke \\ Universidad de Hamburgo. \\ Departamento de Historia
}

Generalmente se supone que la historia política del Perú en el siglo XIX se caracterizó por la inestabilidad y la fragmentación del espacio político. Sin embargo, esta aserción no se basa en investigaciones de historia política sino exclusivamente en estudios de historia económica, social y de las mentalidades. Dirigiendo nuestra atención hacia la historia política, salta a la vista que el sistema constitucional logró pacificar las luchas de modo que en los años setenta se gozó de una estabilidad política hasta entonces desconocida. Todo ello se debió principalmente a la acción política cohesionada de la burguesía limeña, que logró usar el aparato estatal para subordinar los poderes provinciales en cuestiones de política nacional.

\section{Introducción}

Existe un consenso general en que la historia política del Perú republicano decimonónico se caracterizó por la falta de estabilidad política y el fracaso de las instituciones constitucionales. Esta visión de la historia peruana se encuentra en los manuales de historia - tanto peruanos como extranjeros- ${ }^{1}$ de ahí que parezca innecesario discutir este tema pues se piensa que los múltiples golpes de Estado, gobiernos de facto y guerras civiles son pruebas suficientes del fracaso político de la República.

Sin embargo, vale la pena examinar con mayor atención los diferentes estudios que han establecido esta interpretación. Se pueden distinguir tres enfoques que no se excluyen mutuamente pero que sí ponen el énfasis en diferentes aspectos del desarrollo histórico. El primer enfoque - estre-

* Este artículo se basa en una investigación más amplia que no hubiera podido ser realizada sin el apoyo del Servicio Alemán de Intercambio Académico (DAAD), la Fundación Friedrich Naumann y la Universidad de Hamburgo.

1 Manrique, Nelson: Historia de la República, Lima, 1995 (t. 4 de: Eduardo Lores [ed.], Nuestra historia); Miller, Rory: "Peru, Bolivien, Chile. 1830-1920", en: Walther L. Bernecker, Raymond T. Buve, John R. Fisher, Horst Pietschmann, Hans-Werner Tobler (eds.): Handbuch der Geschichte Lateinamerikas, t. 2, Stuttgart, 1992, págs. 619-679; Bonilla, Heraclio: "Peru and Bolivia from Independence to the War of the Pacific", en: Leslie Bethell (ed.): The Cambridge History of Latin America, t. 3, Cambridge, 1985, págs. 539-582. 
chamente vinculado a la teoría de la dependencia - analiza los ramos exportadores de la economía peruana. ${ }^{2}$ Como los productos exportados eran casi exclusivamente materias primas (guano, salitre, lana, plata, etc.) que se podían generar sin grandes inversiones en infraestructura, se llega a la conclusión que los grupos exportadores no tenían interés alguno en el desarrollo de su país. Por eso, se dice, no surgió una "burguesía nacional" sino una "burguesía rentista y parasitaria", ${ }^{3}$ interesada más por la moda de París que por la suerte de sus compatriotas y que, por lo tanto, no se esforzó lo más mínimo en establecer un sistema político sólido en el Perú.

El segundo enfoque no presta mucha atención a la economía de exportación sino que centra su interés en los desarrollos regionales. Como varios estudios han mostrado que los ciclos económicos de una región no concordaban con los de otra, de modo que el auge de una región iba paralelo a la depresión de otra, se ha llegado a la conclusión que para el siglo XIX no se puede hablar de una historia peruana sino de diferentes historias regionales. De esto se deduce que la vida política nacional estaba totalmente fragmentada y que la inestabilidad política se explique por esta desarticulación del espacio político. ${ }^{4}$

El tercer enfoque explica la falta de estabilidad política con la mentalidad tradicional de los peruanos del siglo XIX. Según esta visión, las pautas liberales de las constituciones políticas no eran aplicables a una sociedad que mantenía estructuras estamentarias del antiguo régimen y que por eso seguía prácticas políticas pre-modernas. En esta interpretación, la inestabilidad política era fruto de la incongruencia entre la realidad política (que seguía siendo tradicional) y las reglas constitucionales liberales que son vistas como un sistema totalmente extraño a la política peruana de entonces. ${ }^{5}$

En cada uno de los tres enfoques se pueden encontrar imprecisiones, contradicciones y errores de detalle. Así, por ejemplo, se ha mostrado recientemente que dentro de los grupos exportadores existían proyectos políticos que tenían como meta principal el desarrollo nacional, circunstancia que no era imaginable para los autores influenciados por la teoría de

2 Yepes del Castillo, Ernesto: Perú. 1820-1920. Un siglo de desarrollo capitalista, Lima, 1972; Bonilla, Heraclio: Guano y burguesía en el Perú, Lima, 1974; íd.: Un siglo a la deriva. Ensayos sobre el Perú, Bolivia y la guerra, Lima, 1980; Cotler, Julio: Clases, Estado y nación, Lima, 1978.

3 Bonilla: Guano y burguesía..., pág. 33.

4 Manrique: Historia de la República, págs. 74s. y 137s.

5 Demélas-Bohy, Marie-Danielle: L'invention politique. Bolivie, Èquateur, Pérou au XIXe siècle, Paris, 1992; Aljovín de Losada, Cristóbal: Representative Government in Peru: Fiction and Reality. 1821-1845, Tesis doctoral, Universidad de Chicago, 1996. 
la dependencia. ${ }^{6} \mathrm{~A}$ su vez, la tesis de los desarrollos regionales se basa solamente en el estudio de dos regiones, de las que una (la sierra central) se ve afectada severamente por las campañas militares de la Independencia y la Guerra del Pacífico, que, sin lugar a dudas, eran acontecimientos de carácter nacional. Contra la tesis de la mentalidad política tradicional se ha argumentado últimamente que en la política peruana se hallaban arraigadas ya antes de la Guerra con Chile estructuras, prácticas y estrategias modernas como por ejemplo la sociedad civil, la organización en partidos políticos y la formación de fracciones en los parlamentos. ${ }^{7}$

A pesar de estas críticas, los tres enfoques aportan interpretaciones importantes para comprender la realidad política del Perú del siglo pasado. Sin embargo, ninguno de los tres se basa en un análisis de la política nacional del Perú. Todos se ocupan de ciclos económicos regionales y nacionales, relaciones sociales a nivel provincial y discursos políticos capitalinos. Ni siquiera se intenta desarrollar algún parámetro para explicar qué significa estabilidad/inestabilidad política. Obviamente se cree que no es necesario ocuparse de la historia política para comprender los desarrollos políticos del siglo pasado. A diferencia de los estudios mencionados, analizaré en las siguientes páginas la política en el decenio anterior a la Guerra del Pacífico. Intentaré demostrar que estos años se caracterizaron por una estabilidad política hasta entonces desconocida y que ésta se produjo principalmente por la subordinación de las elites locales a la burguesía limeña en cuestiones de trascendencia nacional.

\section{La estabilidad constitucional}

Se supone generalmente que la traumática derrota en la Guerra del Pacífico fue una consecuencia lógica de las luchas fratricidas en el Perú. Esta interpretación apareció por primera vez poco tiempo después de la guerra y es aceptada hasta hoy en día. ${ }^{8}$ Puede tener algún fundamento en

6 Gootenberg, Paul: Imagining Development. Economic Ideas in Peru's 'Fictious Prosperity' of Guano. 1840-1880, Berkeley y Los Angeles, 1993.

7 McEvoy, Carmen: La utopía republicana. Ideales y realidades en la formación de la cultura política peruana (1871-1919), Lima, 1997; Mücke, Ulrich: Der Partido Civil in Peru. 1871-1879. Zur Geschichte politischer Parteien und Partizipation in Lateinamerika, Stuttgart, 1998.

8 González Prada, Manuel: "Discurso en el Politeama", págs. 65s., en íd.: Obras completas, t. 1, Lima, 1946, págs. 63-71 (el discurso es de 1888); Demélas-Bohy: L'invention politique, pág. 473; Manrique: Historia de la República, págs. 153 y 158s. 
las realidades sociales, económicas y regionales pero carece de una base empírica en la historia política. Desde cualquier punto de vista político, los diez años precedentes a la Guerra del Pacífico se caracterizaron por su estabilidad. Regía desde 1860 una constitución que sólo por algunos meses no estuvo en vigencia en 1867. Ninguna constitución anterior había regido tantos años. En 1920 se abolió la constitución de 1860 siendo la carta política que más años ha estado vigente en toda la vida republicana hasta el día de hoy. Pero la estabilidad no se expresaba simplemente en la continuidad constitucional. Por primera vez en la vida republicana se realizaron dos cambios presidenciales consecutivos por vía de elecciones (1872 y 1876). En 1872 ganó también por primera vez un candidato de la oposición las elecciones presidenciales siendo al mismo tiempo el primer civil que iba a llevar la banda bicolor. Aparte de las elecciones presidenciales, de 1868 hasta 1878 se realizaron cada dos años elecciones para diputados y senadores en diferentes provincias y departamentos del país. Como las campañas electorales generalmente abarcaron un espacio de seis (para congresistas) a 18 meses (para presidentes), se puede concluir que durante la mitad del tiempo en los años setenta se llevaron a cabo campañas electorales, por lo menos en algunos departamentos. A estas elecciones se sumaban las de los concejos provinciales y departamentales según la Ley de Municipalidades de 1873, que se realizaban simultáneamente a las elecciones de carácter nacional. ${ }^{9}$ Vale decir que en los años setenta la práctica de las elecciones desarrolló una continuidad hasta entonces desconocida y que no fue interrumpida por cambios de poder inconstitucionales. ${ }^{10}$

Esto no quiere decir que no hubiera levantamientos en la época. Siguieron produciéndose pero generalmente carecían de una perspectiva política nacional. Se trataba de protestas locales contra alguna medida específica, de luchas entre grupos provinciales o de aventuras personales sin ninguna posibilidad de éxito a nivel nacional.

Contra esta aserción, se ha sostenido la tesis que los levantamientos de Nicolás de Piérola en 1874, 1876 y 1877 sí tuvieron importancia nacional poniendo en peligro el gobierno central. ${ }^{11}$ Sin embargo, es difícil encon-

9 Ley orgánica de municipalidades de 9 de abril de 1873 en Evaristo San Cristóval: Manuel Pardo y Lavalle. Su vida y su obra, Lima, 1945, págs. 380-402.

10 Mücke: Der Partido Civil in Peru..., págs. 143-186.

11 Demélas-Bohy: L'invention politique, pág. 472; Serena Fernández Alonso: "Las montoneras como expresión política armada en el camino hacia la constitucionalidad del Perú republicano. Siglo XIX”, Anuario de Estudios Americanos, 50, 1 (Sevilla, 1993), págs. 165-180. 
trar alguna base para sostener tal tesis. Ninguna de las aventuras de Piérola reunió un número elevado de personas armadas. En ningún momento, Piérola logró dominar alguna zona importante del país y tampoco hubo levantamientos significativos en su apoyo. Algunos de los pronunciamientos que ahora son caracterizados como pierolistas, no lo fueron sino que aprovecharon simplemente una coyuntura propicia para llamar la atención hacia reclamos personales..$^{12}$ Las acciones armadas de Piérola antes de la Guerra con Chile tenían una importancia tan reducida que hasta un historiador pro-pierolista como Alberto Ulloa Sotomayor habla de la "impotencia", el "aislamiento" y la "vanidad pretenciosa" de Piérola en estos años. ${ }^{13}$

Las luchas políticas de los años setenta se diferencian de las anteriores por el hecho de que no pudieron derrumbar el gobierno central y en consecuencia las vías constitucionales alcanzaron una importancia que antes no habían tenido. Como los pronunciamientos de las décadas anteriores habían tenido su base, sin excepción, en provincias alejadas de Lima, la causa principal de esta estabilidad política se debía a una redefinición de las relaciones entre el gobierno central y los poderes regionales. Esta redefinición no se puede comprender sin un análisis de la Constitución de 1860.

La Carta fundamental de 1860 fue un compromiso entre posiciones liberales y conservadoras. Los liberales se imponían en cuestiones como los derechos ciudadanos, la abolición de la esclavitud y los fueros eclesiásticos. Los conservadores se impusieron en las atribuciones del presidente de la República. El texto constitucional se refiere al presidente como "Jefe del Poder Ejecutivo" y no menciona otro cargo bajo el título "Poder Ejecutivo". ${ }^{14}$ El presidente tenía una extensa gama de atribuciones. Le correspondía "hacer ejecutar las leyes y demás resoluciones del Congreso, y dar decretos [...] para su mejor cumplimiento" y requerir a los jueces "la exacta administración de la justicia". ${ }^{15}$ Los nombramientos de los vocales y fiscales de la Corte Suprema se llevaban a cabo a propuesta del presidente de la República, y los nombramientos para cargos menores en la judicatu-

12 Véase Archivo General de la Nación, Cartas de Manuel Pardo, 4-299, Pedro Fernández Baca, 9 de diciembre de 1874 y 12 de diciembre de 1874 (El título de la colección no es correcto tratándose de cartas $a$ y no de Manuel Pardo).

13 Ulloa Sotomayor, Alberto: Don Nicolás de Piérola, Lima (2. a ed.), 1981, págs. 196s. Veáse tambien: Basadre, Jorge: Historia de la República del Perú, ts. 6 y 7, Lima (6. a ed.), 1969.

14 Hay títulos separados sobre otros ramos del poder ejecutivo llamados "De los Ministros de Estado", "Régimen interior de la República" y "Fuerza pública". La Constitución se cita según la edición de Pareja Paz-Soldán, José: Las Constituciones del Perú, Madrid, 1954.

15 Constitución política de 1860 , Art. 93, párrafos 5 y 7. 
ra se realizaban por él mismo a propuesta de la instancia superior respectiva. ${ }^{16}$ El mando de las "fuerzas de mar y tierra" y la movilización de la Guardia Nacional eran asimismo atribuciones del presidente. ${ }^{17}$ Le competían también "la recaudación e inversión de las rentas públicas", el nombramiento de los ministros de Estado y agentes diplomáticos y, además, gozaba de varias atribuciones importantes para las relaciones exteriores y con la Iglesia. ${ }^{18}$ Una de las atribuciones más importantes para el poder presidencial era - aparte de su mando militar - el derecho de nombrar los prefectos y subprefectos que, a su vez, nombraban a los gobernadores. ${ }^{19}$ Como el Perú se dividió en departamentos gobernados por prefectos, provincias gobernadas por subprefectos y distritos gobernados por gobernadores, el derecho de nombrar prefectos y subprefectos significó que el presidente controlara todo el poder ejecutivo puesto que las municipalidades, concejos provinciales y departamentales tenían atribuciones administrativas de poca importancia sin llegar a tener ingresos suficientes para asumir funciones más importantes hasta la Guerra con Chile. ${ }^{20}$ Por eso, el poder del presidente no estuvo limitado por ninguna institución dentro del poder ejecutivo. La división de los poderes fue una división entre el legislativo, judicial y ejecutivo. Dentro del ejecutivo el poder se centralizó en el presidente lo que equivalió a centralizar el poder en Lima.

La Constitución instauró una centralización parecida para los poderes judicial y legislativo pero sin llegar a los extremos centralizadores observados en el poder ejecutivo. Los vocales y fiscales de las cortes superiores en los departamentos sí eran propuestos por la Corte Suprema de Lima y nombrados por el presidente de la República. Sin embargo, era casi imposible despedir legalmente a un vocal o un fiscal de una corte superior. ${ }^{21} \mathrm{De}$ ahí que los miembros de las cortes superiores gozasen, según la ley, de una independencia de las instituciones capitalinas bastante amplia. El Congreso, a su vez, no era una institución muy centralista aunque se reunía en la capital. La mayoría de los congresistas no provenía de Lima y sólo llegaba a la capital para las sesiones parlamentarias. Por eso, los diputados y sena-

16 Ibídem, Art. 126.

17 Ibídem, Art. 93, párrafos 9 y 10.

18 Ibídem, Art. 93, párrafos 6 y 11-18.

19 Ibídem, Art. 115.

20 Los únicos concejos que administraban ingresos elevados eran los de Lima y del Callao. Ministerio de Gobierno, Policía, Obras Públicas, Estadística y Correo: Estadística del Estado del Perú en 1878 a 1879 [sic], Lima, 1879, págs. 289-374.

21 Constitución política de 1860, Art. 130. 
dores no podían dejar de lado los intereses de las provincias y los departamentos cuya representación se les había otorgado.

Los extensos poderes del presidente de la República tenían como consecuencia que la Administración departamental no gozase de independencia alguna. De ahí que un cambio de presidente generalmente significara un cambio de la mayoría de los prefectos y subprefectos. Cuando Manuel Pardo asumió la Presidencia en 1872, el diario oficial El Peruano notificaba el cambio de las dos terceras partes de los prefectos y subprefectos en un período de seis meses. ${ }^{22}$ Considerando que El Peruano no dio parte de todos los cambios, se llega a la conclusión que muy pocos prefectos y subprefectos sirvieron tanto bajo la presidencia de Manuel Pardo como bajo la de su predecesor José Balta. Parece innecesario mencionar que los nuevos funcionarios eran partidarios de Manuel Pardo. El nuevo prefecto del Cuzco, por ejemplo, el teniente coronel Baltazar La Torre era miembro fundador del Partido Civil que llevó Manuel Pardo a la Presidencia. Los prefectos de Puno y Arequipa, Miguel San Román y Juan Corrales Melgar respectivamente, habían tenido puestos destacados en la organización de la campaña electoral de Manuel Pardo en los departamentos mencionados.

\section{Poder personal y Administración pública}

Para comprender las relaciones de poder entre el Estado central y las elites provinciales, no basta con interpretar la Constitución y conocer los cambios en el personal subalterno que traía consigo un nuevo presidente. En la realidad política, el poder del presidente no fue tan extenso como debería ser según el texto constitucional. El Estado central no era capaz de imponer su autoridad en todas las zonas del país y necesitaba, por eso, la colaboración de los notables de provincia. De ahí que un presidente de la República no pudiera escoger libremente los prefectos y subprefectos. Más bien tenía que escoger una persona que por su posición social y por su personalidad ya gozase de algún respeto en la zona que se le iba a conferir. Puesto que cualquier funcionario no servía sólo al Estado sino más concretamente a la persona que ocupaba la presidencia, aceptar un cargo equivalía a apoyar al presidente de turno en una región específica con su prestigio e influencia social. El presidente tenía que ganarse en todos los departamentos personas

22 El Peruano, 6 de agosto de 1872 al 8 de febrero de 1873. 
influyentes que le apoyaran. Si no lograba formar una red de apoyo a nivel nacional, peligraba su propia presidencia puesto que era prácticamente imposible controlar desde Lima levantamientos que estuvieran apoyados en varias regiones del país. En la realidad política, la posición del presidente resultó ser mucho más débil que en el texto constitucional.

A causa de esta debilidad del Estado central, muchas veces las personas llamadas a ser prefectos exigían privilegios que no formaban parte de su cargo. Algunas veces, había verdaderas negociaciones entre el presidente de la República y una persona particular que había sido llamada para ocupar una prefectura. Un ejemplo muy ilustrativo es el caso de Juan Mariano de Goyeneche. Éste había sido presidente del club electoral de Arequipa que apoyaba a Manuel Pardo en la campaña de 1871/72. Goyeneche pertenecía a una de las familias peruanas más acomodadas y distinguidas. Su influencia política y social en Arequipa, una ciudad con apenas veinte mil habitantes, era enorme. El mismo Goyeneche se vanagloriaba de que Pardo había ganado la elección en Arequipa por las muchas influencias que él, Goyeneche, tenía en la ciudad blanca. ${ }^{23}$ Aunque esto no era del todo correcto, no había lugar a dudas de que en una ciudad tradicional y católica, Goyeneche - personaje muy pegado a la Iglesia - era una persona importantísima para el presidente liberal Manuel Pardo. Muchas veces, Arequipa había sido el centro de levantamientos y, de hecho, el último presidente liberal, Mariano Ignacio Prado, cayó por una insurrección arequipeña. Goyeneche como prefecto hubiera sido la solución ideal para un gobierno liberal porque Goyeneche era capaz de asegurar la lealtad de gran parte de los arequipeños conservadores.

Pocos meses después de inaugurar su mandato, Pardo ofreció a Goyeneche la prefectura de Arequipa. Goyeneche no contestó ni "sí" ni "no" sino que empezó a solicitar diferentes puestos administrativos para amigos suyos exigiendo a la vez que Pardo impidiera cualquier celebración del segundo aniversario nacional italiano. ${ }^{24}$ Cuando Pardo pidió explícitamente que Goyeneche se pronunciara acerca de la prefectura, éste contestó que la aceptaba siempre y cuando pudiera seguir siendo miembro del par-

23 AGN, Cartas de Manuel Pardo, 19-1327, Juan Mariano de Goyeneche, 2 de abril de 1872. Las cartas de Juan Mariano de Goyeneche a Manuel Pardo han sido publicadas por Rosas Siles, Alberto: "Epistolario de don Juan Mariano de Goyeneche y Gamio", Revista del Archivo General de la Nación, 9 (Lima, 1986), págs. 169-233.

24 Ibídem, 24 de agosto de 1872, 30 de agosto de 1872, 3 de septiembre de 1872, 4 de septiembre de 1872,8 de septiembre de 1872,10 de septiembre de 1872 y 15 de septiembre de 1872 . 
lamento nacional, circunstancia prohibida expresamente por la Constitución. ${ }^{25}$ Por esta razón, Pardo no pudo aceptar dicha condición y, sin embargo, decidió nombrar a Goyeneche como prefecto de Arequipa aun sin tener su consentimiento. ${ }^{26} \mathrm{El}$ resultado fue que el prefecto de Arequipa, Juan Corrales Melgar, renunció a su puesto sin que Goyeneche aceptase la prefectura de modo que el prefecto de facto renunciaba mientras que el prefecto nombrado rehusaba ponerse a la cabeza de la prefectura. ${ }^{27}$

Goyeneche no hacía nada para resolver este problema, sino al contrario: trataba de desestabilizar la situación política en Arequipa imprimiendo volantes en los cuales se acusaba al prefecto Corrales Melgar de haber cometido una serie de abusos. De este modo, la autoridad de Corrales Melgar seguía deteriorándose y ya se rumoreaba que iba a haber un levantamiento en la ciudad blanca. ${ }^{28}$ En esta situación bastante crítica para el gobierno central, Goyeneche ofreció aceptar la prefectura si Pardo le apoyaba económicamente y le dejaba mano libre para escoger los funcionarios que servían en Arequipa. Las exigencias de Goyeneche eran excesivas. En cuestiones económicas, Goyeneche pidió que Pardo garantizara medios para proyectos de construcción que el mismo Goyeneche aún no conocía. Además, exigía que Pardo le diera 100.000 soles.

"Este dinero lo necesito [...] para comprar a los que por hallarse ofendidos y habiendo sido nuestros se nos han separado y hoy están en la revolución y si no fuese necesario comprar a los individuos que llevo dicho, esa plata la necesito para empezar a hacer bienes a los pueblos desde el día que me reciba de Prefecto dándoles algo para sus templos destruidos o para alguna obra pública." ${ }^{29}$

Goyeneche prometió dar cuenta del empleo del dinero pero por sus mismas palabras resulta obvio que él quería decidir la distribución de esos fondos. En cuestiones administrativas, Goyeneche quiso poder escoger los subprefectos en el departamento de Arequipa, los empleados de la aduana (que era la segunda más importante del país), de la prefectura y de la beneficencia. Además, Pardo tendría que asegurar que todos los detenidos que Goyeneche fuese a mandar a Lima, no regresarían a Arequipa.

25 Ibídem, 17 de septiembre de 1872; Art. 50 de la Constitución política de 1860. 1872.

26 AGN, Cartas de Manuel Pardo, 19-1327, Juan Mariano de Goyeneche, 11 de octubre de

27 El Peruano, 26 de octubre de 1872. La renuncia de Corrales Melgar se realizó el 8 de octubre de 1872 .

28 AGN, Cartas de Manuel Pardo, 7-433, Manuel F. Benavides, 13 de diciembre de 1872.

29 AGN, Cartas de Manuel Pardo, 19-1327, Juan Mariano de Goyeneche, 12 de diciembre de 1874 . 
Para dar más peso a sus exigencias, Goyeneche organizó una manifestación en Arequipa en la que se le pedía que tomara la prefectura. Según las palabras del mismo Goyeneche, esta manifestación le había costado mil "pesos". ${ }^{30}$ En un discurso dirigido a los manifestantes, comentaba que había informado al presidente sobre sus "pedidos" y que iba a aceptar la prefectura en el caso que Pardo cediera a ellos. ${ }^{31}$ De este modo, la situación para el Gobierno central se había vuelto bastante precaria. Si Pardo aceptaba las exigencias de Goyeneche, iba a ceder su poder en Arequipa. Pero si no aceptaba, corría el peligro de verse enfrentado a un levantamiento de los grupos más conservadores de Arequipa, circunstancia que le podía costar la presidencia.

Finalmente, Pardo no aceptó todas las exigencias de Goyeneche por lo cual éste le informó que no iba a hacerse cargo de la prefectura. ${ }^{32}$ Pardo no podía aceptar las exigencias económicas puesto que el presupuesto de la República se aprobaba por el Congreso y, según la ley, el presidente no podía disponer libremente de 100.000 soles. Aunque Pardo rechazó las pretensiones económicas, sí aceptó la solicitud de poder escoger al personal subalterno. ${ }^{33}$ Es decir, Pardo estaba dispuesto a abdicar su derecho constitucional de elegir los subprefectos y otros funcionarios estatales. Aunque la Constitución estipulaba que el presidente eligiera libremente los prefectos y subprefectos, de hecho tenía que nombrar prefectos con influencia en el departamento respectivo y ellos, a su vez, podían exigir el derecho de elegir los subprefectos. La solicitud de Goyeneche no fue ninguna excepción. El prefecto de Cuzco, el coronel Baltazar La Torre, parece haber tenido también el libre poder de escoger subprefectos. Cuando en 1873 Pardo aprovechó la ausencia de La Torre de la capital departamental para nombrar nuevos subprefectos en Chumbivilcas y Canchis (Dávila y Coello, respectivamente), La Torre escribió al presidente: "Hágame U. el favor de colocar de otra manera a Dávila y a Coello: no los quiero. No creo haberlo hecho tan mal hasta ahora que haya sido preciso restringir las concesio-

30 Ibídem, 21 de diciembre de 1872. La moneda peruana se había cambiado de soles a pesos en 1863, equivaliendo 1,25 pesos a un sol de plata. El sol de plata a su vez equivalía al $5 \%$ de un sol de oro, es decir un sol de plata tenía el valor de 1,5 gramos de oro puro. Gálvez Delgado, Jaime: "Elites, estado y control financiero", pág. 150, en Banco Central de Reserva del Perú, Agencia para el Desarrollo Internacional (eds.): Apuntes sobre el proceso histórico de la moneda. Perú: 1820-1920, págs. 141-168.

31 AGN, Cartas de Manuel Pardo, 7-433, Manuel F. Benavides, 17 de diciembre de 1872.

32 AGN, Cartas de Manuel Pardo, 19-1327, Juan Mariano de Goyeneche, 24 de diciembre de 1872 .

33 Ibídem, 27 de diciembre de 1872. 
nes que me hizo $U$. antes de salir de Lima [para hacerme cargo de la Prefectura, U.M.]." ${ }^{34}$ La Torre amenazó con renunciar a la prefectura si Pardo insistía en los nombramientos ${ }^{35}$ Como La Torre murió poco después, no sabemos quien se hubiera impuesto en este conflicto. Sin embargo, es evidente que La Torre tenía mucho más poder del que le correspondía según la Constitución. Este poder no emanaba de una base legal sino de convenios informales y verbales con el presidente. Por eso, la balanza de poder entre el presidente y el prefecto estaba expuesta a cambios abruptos. Pardo aprovechó una expedición de La Torre a la selva amazónica para tratar de quitarle el poder que unos meses antes le había conferido.

Otros prefectos estaban más subordinados al presidente de la República. El prefecto de Puno, Miguel San Román, no podía escoger por ejemplo por sí solo nuevos subprefectos. A veces, los subprefectos propuestos por San Román no eran aceptados por Pardo y aquél tenía que aceptar una persona que no le convenía mucho. ${ }^{36}$ Entonces no es posible hablar de una relación uniforme entre el presidente de la República y los prefectos. Más bien, cada prefecto tenía autorizaciones específicas que, a su vez, podían variar durante su mandato. La Constitución no determinaba la relación entre presidente y prefecto pero sí sirvió de base para las negociaciones. Goyeneche quería decidir sobre los nombramientos de los subprefectos en el departamento de Arequipa, circunstancia que suponía reconocer o aceptar que esta facultad le correspondía a Pardo, quien podía — sin base legal, es decir informalmente - transferirla a una persona subalterna.

\section{El poder del presidente}

Resulta extraño que personas tan influyentes como por ejemplo Juan Mariano de Goyeneche o Miguel San Román no lograran imponerse de una manera mucho más clara sabiendo que el presidente dependía de su apoyo. La fuerza del presidente consistía en la desunión de los notables provinciales. En la mayor parte de las provincias andinas, los terratenientes no tenían relaciones amigables entre sí sino que competían por tierra, agua, mano de obra y poder. El resultado eran querellas entre diversas familias o clanes que

34 AGN, Cartas de Manuel Pardo, 23-1545, Baltazar La Torre, 2 de junio de1873.

35 Ibídem, 2 de junio de 1873 y 7 de junio de 1873.

36 AGN, Cartas de Manuel Pardo, 25-1710, Miguel San Román, 13 de junio de 1873, 27 de junio de 1873,11 de julio de 1873,5 de agosto de 1873 y 8 de agosto de 1873 . 
solían limitarse al ámbito de una provincia pero que a veces llegaron a tener repercusiones mucho más importantes. A menudo, el poder central no intervenía para resolver esos conflictos pero sí influía en su desenlace nombrando subprefectos, jueces, gobernadores y oficiales de policía. Estos nombramientos - hechos directamente por el gobierno central o por una persona subalterna- tenían gran importancia. En primer lugar, algunos cargos implicaban la disposición sobre ingresos regulares y/o el mando sobre fuerzas armadas y, en segundo lugar, un nombramiento significaba que la persona nombrada mantenía buenas relaciones con el poder central y por eso, podía solicitarle que le apoyara, sea con medios económicos o con fuerza militar. Por lo tanto, el poder de un prefecto, por ejemplo, no emanaba sólo de los medios sobre los que disponía directamente, sino también de la expectativa que el gobierno central le apoyara en un conflicto importante.

Por eso, las fracciones locales luchaban por puestos aparentemente poco importantes. Pedro Fernández Baca, oriundo de la provincia Paruro en el Cuzco, escribió lo siguiente al presidente de la República, Manuel Pardo:

“... suplico a U. encarecidamente que de ningún modo sea nombrado D. Isidoro Castilla Juez de Paruro pues éste es un hombre muy corrompido, estúpido y bárbaro. Tiene una numerosa familia infernal en la provincia, cometería mil iniquidades y sería la mayor desgracia para mi provincia Paruro tener un Juez como Castilla ..." ${ }^{37}$

En la provincia cuzqueña de Acomayo, el subprefecto Nicanor Dueñas trató de impedir que uno de sus enemigos personales se encargara de la alcaldía del concejo provincial:

“... en esta provincia de mi cargo me hallo en una intransigente rivalidad con Juan Andrés Escalante, suegro del Diputado Emilio Luna, de las mismas tendencias y condiciones que éste, que enrolado en la pasada revolución [de, U.M.] Salas se ha declarado enemigo de la autoridad política y como este Escalante es Alcalde del Consejo Provincial le he acusado por justas y comprobadas faltas del cumplimiento de sus deberes ...."38

El juicio no se llevó a cabo porque el juez competente se fugó de la provincia. En 1876, el nuevo presidente encargó la subprefectura a un miembro de la familia Luna por lo cual Nicanor Dueñas escribió a Manuel Pardo pidiéndole ayuda. ${ }^{39}$

37 AGN, Cartas de Manuel Pardo, 4-299, Pedro Fernández Baca, 24 de octubre de 1873.

38 AGN, Cartas de Manuel Pardo, 26-1089, Nicanor Dueñas, 20 de junio de 1873.

39 Ibídem, 7 de marzo de 1875 y 29 de septiembre de 1876. 
En Puno se enfrentaban las familias Lizares y Quiñones de Azángaro por un lado y la familia San Román de Lampa por el otro. ${ }^{40}$ Como las tres familias tenían grandes haciendas y ejercían mucha influencia en el departamento, sus querellas repercutían en la balanza del poder. El nombramiento de Miguel San Román como prefecto le dio una gran ventaja en sus pleitos personales. Intentaba impedir, por ejemplo, que ninguna persona vinculada a las familias Lizares y Quiñones ganara un escaño en el Congreso. Para las elecciones de diputados en 1873, el prefecto mandó tropas a la provincia de Azángaro argumentando que iban a garantizar la limpieza de las elecciones. A pesar de que Quiñones había protestado contra esta medida en una carta al presidente, las elecciones en Azángaro se realizaron bajo la vigilancia de una fuerza militar impresionante y ningún familiar o aliado de las familias Quiñones y Lizares salió elegido. ${ }^{41}$

San Román cuidaba mucho que todos los nombramientos en Azángaro recayeran en personas adversarias a Quiñones y Lizares. Por haber decidido un juicio en favor de los dos, el juez de Azángaro fue detenido. San Román propuso en su reemplazo un pariente suyo, Daniel Rosel y Salas. ${ }^{42}$ El marido de una cuñada de San Román defendía esta acción escribiendo que no era aceptable que un juez de Azángaro defendiese los intereses de los Lizares y Quiñones. ${ }^{43}$ En 1875, San Román llegó al extremo de relevar de su cargo al subprefecto de Azángaro, Montoya, sin haber consultado al presidente Pardo. Según San Román, Montoya era muy débil para sobrellevar los conflictos con Quiñones y Lizares. En lugar de Montoya, San Román encargó la subprefectura a José Cáceres lo que motivó una nueva protesta de Quiñones. ${ }^{44}$

A partir de 1875 empezó a cambiar la balanza de poder en Puno. Primero, Manuel Pardo restituyó a Montoya en su cargo y quitó la prefectura a San Román. ${ }^{45}$ En las elecciones de 1875, Montoya fue atacado por un ejército particular de 200 hombres liderados por Quiñones y Lizares que triunfaron después de un combate que costó la vida a seis personas. El nue-

40 Sobre las familias Quiñones y Lizares, véase Jacobsen, Nils: Mirages of transition. The Peruvian Altiplano. 1780-1930, Berkeley y Los Ángeles, 1993, págs. 239s.; Tamayo Herrera, José: Historia social e indigenismo en el altiplano, Lima, 1982, págs. 162-170.

41 AGN, Cartas de Manuel Pardo, 40-2732, Miguel San Román, 29 de septiembre de 1873, 17 de octubre de 1873,3 de noviembre de 1873 y 10 de noviembre de 1873 .

42 Ibídem, 7 de noviembre de 1873.

43 AGN, Cartas de Manuel Pardo, 5-323, Francisco Ballón, 28 de noviembre de 1873.

44 AGN, Cartas de Manuel Pardo, 40-2732, Miguel San Román, 27 de abril de 1875 y 8 de mayo de 1875

45 AGN, Cartas de Manuel Pardo, 18-1286, Juan Gastó, 7 de septiembre de 1875. 
vo prefecto Gastó pudo detener pocos días después a los dos líderes. Sin embargo, las elecciones no se anularon y tampoco se entabló juicio alguno contra ellos. ${ }^{46}$ En 1876 el nuevo presidente Mariano Ignacio Prado encargó la prefectura a Quiñones, quien ahora podía usar los medios económicos y militares vinculados con este cargo para combatir a San Román. ${ }^{47}$

Todos los conflictos descritos aquí tenían carácter local. No se trataba de luchas políticas a nivel nacional, sino de problemas entre diferentes fracciones dentro de una provincia o de un departamento. El gobierno central no había generado estos conflictos y tampoco era capaz de resolverlos. De todas maneras, tenía los medios para apoyar una banda u otra y así inclinar la balanza en favor de una de las dos. Por esta razón, los notables de provincia tenían mucho interés en ganarse las simpatías del gobierno central y ocupar cargos administrativos. Éstos eran una muestra de estar vinculados con el gobierno central y, en algunos casos, implicaban el manejo de fondos, que a su vez podían ser utilizados para fortalecer la clientela propia. Para sobrevivir en las luchas provinciales, los notables necesitaban contactos con el poder central, sea directamente con el Gobierno, sea indirectamente con alguna persona influyente en la política nacional, vale decir limeña. Prescindir de estos contactos a nivel nacional, significaba poder perder su posición social a nivel local. De ahí que los notables provinciales buscasen el apoyo del gobierno central.

\section{Guano y burguesía}

Para comprender el juego político a nivel nacional en el siglo XIX, hay que analizar las relaciones entre el gobierno central y/o líderes políticos nacionales por un lado y notables provinciales por el otro. ${ }^{48}$ El poder político se basaba en estas relaciones de modo que la importancia política de un personaje se podía medir -teóricamente- por la cantidad de sus contactos. El poder del Estado estaba aún estrechamente vinculado con el poder particular de que disponían los hombres que se encontraban a la cabeza de la administración pública. Un presidente era poderoso siempre

46 Ibídem, 16 de noviembre de 1875, 19 de noviembre de 1875, 30 de noviembre de 1875 y 14 de diciembre de 1875; AGN, Cartas de Manuel Pardo, 40-2732, Miguel San Román, 29 de noviembre de 1875 .

47 AGN, Cartas de Manuel Pardo, 5-323, Francisco Ballón, 23 de mayo de 1878.

48 De un modo ejemplar, este tipo de relaciones fue analizado para los casos de Méjico y Brasil. Véase Guerra, François-Xavier: Le Mexique. De l'ancien régime a la révolution, 2 ts., París, 1985; Graham, Richard: Patronage and Politics in Nineteenth-Century Brazil, Stanford, 1990. 
y cuando tuviese una serie de contactos con personas influyentes en diversas regiones del país. Ningún presidente podía prescindir de estas alianzas con las elites provinciales apoyándose exclusivamente en los medios de poder del aparato estatal. Por eso, se puede decir que la independencia del Perú significaba una ruralización del espacio político. Mientras que antes el poder político residía en Lima, en el Perú independiente, el poder político se encontraba en el campo. Pero a partir de los años sesenta, Lima volvía a ganar importancia en el juego político y las elites provinciales empezaban a perder, poco a poco, la preponderancia. La estabilidad política en los años setenta fue un resultado de estos cambios en la balanza del poder.

El nuevo poder de Lima se debía en gran parte al boom del guano. Este fertilizante natural se empezó a exportar a partir de los años cuarenta en grandes cantidades. Como el guano se encontraba en islas no habitadas era propiedad del Estado central que, de este modo, había encontrado un ingreso enorme que, a diferencia del tributo de indios, no se recolectaba por las elites provinciales. Entonces, el guano independizó económicamente al gobierno central de los notables andinos. No resulta extraño por eso, que el tributo de indígenas fuese abolido en 1854. El Estado central ya no dependía de este ingreso puesto que cinco años antes se había otorgado un monopolio de exportación de guano a la casa inglesa Gibbs que tenía como resultado una multiplicación de las cantidades exportadas y de los ingresos del gobierno central. ${ }^{49}$

Los ingresos guaneros no quedaron en las arcas del erario público sino que fueron distribuidos de una manera bastante generosa entre un grupo muy reducido de comerciantes y agricultores. Éstos fueron beneficiados por la llamada consolidación de la deuda interna (en la cual se distribuyeron 23 millones de pesos), por la liberación de esclavos (por la cual se pagaron 7,5 millones de pesos) y por varias concesiones de exportación de guano a mercados secundarios..$^{50}$ La mayor parte de los beneficiados vivía en Lima o en los valles cercanos. En los años cincuenta, llegaron a acumular un capital tan importante que en 1862 un grupo de ellos podía conseguir el derecho exclusivo de exportación de guano a Inglaterra, el mercado más

49 Acerca de la exportación de guano véase Basadre: Historia de la república, ts. 3-6; Bonilla: Guano y burguesía en el Perú; Hunt, Shane: "Guano y crecimiento en el Perú del siglo XIX", Revista Latinoamericana de Historia Económica y Social, 4 (Lima, 1984), págs. 35-92; Mathew, W. M.: The House of Gibbs and the Peruvian Guano Monopoly, London, 1981; Yepes del Castillo: Perú. 1820-1920.

50 Véase Quiroz, Alfonso W.: La deuda defraudada. Consolidación de 1850 y dominio económico en el Perú, Lima, 1987; Aguirre, Carlos: Agentes de su propia libertad. Los esclavos de Lima y la desintegración de la esclavitud. 1821-1854, Lima, 1993. 
importante. ${ }^{51}$ En los diez años siguientes, el flujo de capital tuvo como consecuencias la fundación de una docena de bancos, una vertiginosa expansión de la agricultura de exportación (azúcar y algodón), la fundación de innumerables empresas no industriales (de servicio público, de seguros, etc.) y la construcción de más de mil kilómetros de líneas ferroviarias.

En resumen, por la exportación del guano surgió una nueva capa social que generalmente es denominada oligarquía pero que más bien era una burguesía mercantil financiera. De todos modos, esta capa social era capitalina. Aunque a menudo se hace hincapié en los efectos económicos del boom del guano, es importante recalcar que la riqueza guanera cambiaba también la estructura y la vida social en Lima..$^{52}$ La llamada oligarquía no era sólo la totalidad de los guaneros, banqueros y terratenientes costeños, sino que formaba a la vez una red social que se encontraba en los clubs recién fundados, leía los mismos periódicos y visitaba los mismos eventos sociales como por ejemplo las regatas y las carreras de caballos. Es decir, a partir de los años cincuenta surgió en Lima una nueva capa social que se caracterizó tanto por sus negocios comerciales como por sus estrechos vínculos en la vida social.

Dentro de esta capa social, llámese oligarquía o burguesía, existió un amplio consenso político que rebasó las diferencias entre conservadores y liberales. Este consenso tenía dos puntos básicos: primero, una política económica de dejar hacer y segundo, el fortalecimiento del Estado central. A primera vista, estos dos puntos parecen contradictorios. Sin embargo, gobiernos estables y paz política eran condiciones básicas para el bienestar de la burguesía limeña puesto que sus inversiones corrían peligro de perderse en cualquiera de los muchos levantamientos. Por eso, desde los años cincuenta empezó a extenderse la convicción de que los cambios de gobierno deberían realizarse por vía pacífica, es decir sin levantamientos armados. Esto se expresaba primero en escritos teóricos y después en la práctica política. Ya en 1855, Juan Espinoza escribió en su Diccionario para el pueblo: "El caudillaje ha salvajizado la pobre América, la ha aniquilado y le ha impedido llenar sus destinos, una vez alcanzada su independencia. ¡Malditos caudillos!"’53 Unos diez años más tarde, Luis Benjamín Cisneros

51 El gobierno otorgó esos derechos a cambio de empréstitos sobre elevadas sumas de modo que sólo casas comerciales con gran capital podían conseguir consignaciones de exportación de guano.

52 Mücke: Der Partido Civil in Peru, págs. 89-113.

53 Espinoza, Juan: Diccionario para el pueblo: Republicano democrático, moral, político y filosófico, Lima, 1855, pág. 139. 
recalcó que para alcanzar el progreso económico deseado era necesario “...vivir veinte años consecutivos — ¡nada más que veinte años! — sin dar el escándalo de nuevas guerras civiles..." ${ }^{4}$

Cuando en 1869 el presidente Balta arrebató el negocio de guano a los comerciantes peruanos para entregarlo a la casa francesa Dreyfus, los comerciantes afectados ni siquiera intentaron derribar a Balta por un levantamiento. Dos años más tarde, el líder de la oposición, Manuel Pardo, escribió a José Antonio de Lavalle: "Coincido completamente en opiniones contigo sobre la incompatibilidad que hay entre las ideas que yo represento y la revolución. Jamás me ha pasado por la imaginación ponerme a la cabeza de ella, cualquiera que fuese el éxito de la lucha [electoral, U.M.] ...." ${ }^{55}$ En 1872, Manuel Pardo llegó al poder precisamente porque el golpe de Estado de la cúpula militar en su contra no encontró ningún apoyo en las filas conservadoras limeñas, que al contrario, condenaron el golpe a pesar de que habían luchado contra la candidatura de Pardo en las elecciones anteriores ${ }^{56}$ Asimismo, un líder de la oposición contra Pardo, Luis Benjamín Cisneros criticó en 1874 los planes revolucionarios de Nicolás de Piérola: “... felizmente para todos, el país soporta tranquilo y resignado [la política equivocada del gobierno, U.M.], con un buen sentido superior a las malévolas instigaciones de los que quieren lanzarlo de nuevo en la senda de la revolución.."57

La riqueza guanera tuvo un impacto indirecto pero importantísimo para la estabilización política. Independizó al Estado central del tributo indígena generado en los Andes (que tampoco se volvió a introducir durante la crisis fiscal en los años setenta) y ayudó a formar una clase política limeña que por su riqueza poseía poder político y que además tenía intereses comunes, como la paz política, a pesar de tener diferencias en cuestiones específicas. La balanza de poder entre el gobierno central y los poderes regionales cambió en las décadas anteriores a la guerra con Chile porque el poder central se basaba cada vez más en el apoyo de grupos

54 Cisneros, Luis Benjamín: "Ensayo sobre varias cuestiones económicas del Perú", pág. 140, en: íd., Obras completas, t. 3, Lima, 1939, págs. 10-140.

55 Archivo de José Pardo y Barreda, Carta del 27 de mayo de 1871, citada en Martin, José Carlos: 1872, Lima, 1974, pág. 11.

56 Véase la lista de los 103 firmantes de la "Protesta del Congreso condenando el movimiento revolucionario de 22 de julio de 1872, ejecutado por una parte de la Fuerza Armada", en Evaristo San Cristóval: Manuel Pardo y Lavalle, págs. 557-559.

57 Cisneros, Luis Benjamín: “QQue no hay remedio?”, pág. 361, en: íd., Obras completas, t. 3, págs. 359-378. 
limeños y en ingresos generados en Lima. Esto no significaba que el gobierno central se independizara de los notables provincianos pero sí que su poder no se sustentaba ya exclusivamente en estas relaciones. Negociando con los poderes regionales, el gobierno central se encontró en una posición mucho más ventajosa que en las primeras décadas posteriores a la independencia.

El fortalecimiento del poder central no llegó hasta el punto que pudiese implementar proyectos políticos específicos en alguna provincia en abierta oposición a la elite local. Exceptuando la construcción de los ferrocarriles, hasta la Guerra del Pacífico se podía hablar de una no-política del gobierno central en las regiones andinas. El Estado central, por ejemplo, no hizo intento alguno de expropiar la iglesia y las comunidades indígenas. Muchos proyectos no se tuvieron en cuenta debido a que las elites provinciales eran capaces de impedir cualquier medida que no les conviniera. Gran parte de las medidas dictadas por el gobierno central simplemente no se aplicaba en las provincias andinas y cuando el gobierno central tomaba la iniciativa para implementar alguna reforma, muchas veces encontraba resistencia activa. Así, por ejemplo, en 1875 se impidió que profesores alemanes mandados por el Gobierno para reformar la enseñanza secundaria realizaran su trabajo en el Cuzco, llegando al extremo de encarcelar a uno de los alemanes ${ }^{58} \mathrm{El}$ año anterior, en Arequipa, se había quemado públicamente el periódico pedagógico El Educador Popular que se editaba por el Gobierno para mejorar la enseñanza. ${ }^{59}$

Esta impotencia del gobierno central era generalmente aceptada y encontró una base legal en la Ley orgánica de municipalidades del 9 de abril de 1873. ${ }^{60}$ Esta ley creó concejos departamentales, provinciales y distritales y les otorgó una gran cantidad de atribuciones de carácter administrativo. La ley equivalía a una promesa del gobierno central de no intervenir en asuntos de ámbito provincial, dicho en palabras de un contemporáneo: “... se dictó la ley que descentraliza la administración de las localidades y por la cual se devuelve a éstas el derecho y la facultad de gobernarse." ${ }^{\prime 1} \mathrm{La}$ idea descentralizadora no tenía nada que ver con los principios federalistas

58 AGN, Cartas de Manuel Pardo, 12-777, Luis del Castillo, 8 de febrero de 1876; 30-2052, Mariano Orihuela, 8 de febrero de 1876.

59 AGN, Cartas de Manuel Pardo, 25-1710, Manuel Masías Llosa, 29 de mayo de 1874; 28-1903, José Moscoso Melgar, 12 de junio de 1874.

60 Ley orgánica de municipalidades de 9 de abril de 1873, en San Cristóval: Manuel Pardo y Lavalle, págs. 380-402.

61 Revista general del año 1873, Lima, 1874 (ed. por El Nacional), pág.18. 
puesto que el gobierno de la República no iba a depender de ningún modo de instituciones departamentales o federales. ${ }^{62}$ Descentralización significó no-intromisión del gobierno central en asuntos provinciales lo que dejó a merced de las elites provinciales la realización de cualquier reforma. ${ }^{63}$

Por un lado, el gobierno central se ausentó de la realización de proyectos políticos a nivel local y por el otro llegó a limitar la influencia de las elites provinciales en cuestiones de carácter nacional. Así por ejemplo en los años setenta, cualquier levantamiento con ambiciones más allá de los límites provinciales era sofocado rápidamente por las fuerzas del orden. El éxito del Gobierno se debió a dos causas. En primer lugar, se llegó a disciplinar el ejército que, a pesar de todas sus deficiencias, superaba el poder militar de cualquier alianza local de terratenientes. En segundo lugar, la construcción del ferrocarril de Mollendo-Arequipa-Puno facilitaba el transporte de las tropas en una zona que hasta entonces había sido el centro de los levantamientos antigubernamentales. En 1874 por ejemplo, el prefecto de Puno podía mandar en un día la tropa estacionada en dicha localidad a la ciudad de Arequipa, circunstancia que quitaba a Piérola cualquier posibilidad de tomar esta importante ciudad sureña por un golpe de mano. ${ }^{64}$

La estabilidad política en los años setenta no se debió a un cambio brusco de la mentalidad política de las elites rurales. No existe base documental para asumir que en los Andes "sectores terratenientes comprometidos con la modernización y la democracia" hubieran tratado de implantar un sistema político más representativo y democrático. ${ }^{65} \mathrm{Al}$ contrario, hasta los aliados del presidente liberal Manuel Pardo tenían visiones políticas bastante tradicionales. El arequipeño Juan Mariano de Goyeneche, por ejemplo, estaba muy vinculado a la Iglesia y se oponía a cualquier medida que afectase al poder religioso. El prefecto de Puno, Miguel San Román se burlaba en sus cartas al presidente de la República de los fundamentos más básicos del sistema republicano, llamando a los principios del Estado de

62 Compárese McEvoy: La utopía republicana, pág. 161.

63 Véase también el debate entre Karen Spalding y Nils Jacobsen en el cual Spalding opinó que las tomas de tierras por terratenientes surandinos desde los años setenta eran posibles gracias al apoyo del gobierno central, mientras que Jacobsen atribuyó la expansión de las haciendas a la demanda creciente de lana en mercados europeos, Spalding, Karen: "Estructura de clases en la sierra peruana. 1750-1920”, Análisis, 1 (Lima, 1977), págs. 25-35; Jacobsen, Nils: "Desarrollo económico y relaciones de clase en el sur andino (1780-1920)", Análisis, 5 (Lima, 1979), págs. 67-81.

64 AGN, Cartas de Manuel Pardo, 40-2732, Miguel San Román, 3 de noviembre de 1874.

65 Carmen McEvoy: La utopía republicana, pág. 140. 
derecho "conceptos podridos" y al Congreso una "demora para la administración". Según San Román, los adversarios políticos eran "ratas" y "reptiles" a los que había que combatir sin consideración de las leyes. ${ }^{66}$

Resulta bastante exagerado hablar de dos modelos políticos enfrentados en los años setenta: el "republicanismo cívico" de Manuel Pardo y el "modelo patrimonalista" formado por Ramón Castilla. ${ }^{67} \mathrm{La}$ estabilidad política de los años setenta no era el resultado de una mayor participación política. En primer lugar, la participación política siempre había sido mucho más grande de lo que generalmente se supone y, en segundo lugar, la burguesía limeña no quería ampliar la participación política. ${ }^{68}$ Resulta mucho más convincente de explicar la estabilidad política con el desarrollo de las relaciones de diferentes grupos de elite a nivel nacional. Así, se puede decir que dentro del mismo sistema político existente desde hace décadas, cambiaba la balanza de poder a favor de un grupo capitalino recién surgido por lo cual algunos aspectos del sistema perdían importancia (los pronunciamientos) mientras que otros la ganaban (las elecciones). Es decir, que la estabilidad política no se debió a un "pacto de elites" ${ }^{69}$, ni a una "convergencia de elites" 70 sino al surgimiento de una nueva elite que logró cooptar miembros de elites provinciales y subordinar de este modo otras fracciones de dichas elites provinciales. Tanto la cooptación como la subordinación se realizaban con medios políticos ya establecidos desde hace décadas, es decir, no era necesario crear una nueva cultura política a nivel nacional para estabilizar el sistema político.

\section{Conclusiones}

Resumiendo los argumentos de este artículo, se llega a la conclusión que los años setenta se caracterizaron por una estabilidad política hasta entonces desconocida. Esta estabilidad se reflejaba en la larga vigencia de la Constitución de 1860, en las múltiples elecciones celebradas y en la imposi-

66 AGN-CCP, 40-2732, Miguel San Román, 1 de marzo de 1873, 20 de junio de 1873, 9 de octubre de 1874 y 9 de febrero de 1875.

67 Carmen McEvoy: La utopía republicana, pág. 437.

68 Mücke: Der Partido Civil in Peru...

69 O'Donnell, Guillermo y Schmitter, Philippe C.: Transitions from Authoritarian Rule: Tentative Conclusions About Uncertain Democracies, Baltimore, 1986, pág. 37.

70 Burton, Michael y Gunther, Richard y Higley, John: "Introduction: Elite Transformations and Democratic Regimes", pág. 24, en: John Higley, Richard Gunther: Elites and Democratic Consolidation in Latin America and Southern Europe, Cambridge, 1992, págs. 1-37. 
bilidad de derrumbar el gobierno central por vía de levantamientos. La estabilidad política se debía en gran parte a la redefinición de las relaciones entre el poder central y los poderes regionales. La Constitución de 1860 concentraba el poder ejecutivo en el presidente de la República que tenía el mando supremo de las fuerzas armadas y nombraba directa o indirectamente a casi todos los funcionarios del poder ejecutivo. Sin embargo, en la realidad política resultó ser mucho más débil de lo que preveía la Constitución. No podía elegir libremente los funcionarios del poder ejecutivo puesto que el poder de un funcionario no emanaba sólo de su puesto sino más bien de su posición social. De ahí que cualquier presidente estaba obligado a buscar miembros de las elites provinciales en todos los departamentos que le apoyaran. La fuerza real del presidente radicaba en el hecho de que los notables de provincia no formaban un bloque homogéneo sino que en cada provincia estaban divididos en diferentes fracciones. Como en muchos casos los cargos públicos implicaban el mando de fuerzas armadas y/o la disposición sobre medios económicos, cualquier notable estaba interesado en ocupar algún cargo público. De este modo existía una dependencia mutua entre el gobierno central y los notables provinciales.

El auge de la exportación guanera no hizo desaparecer esta dependencia mutua pero sí la cambió reforzando la posición del gobierno central básicamente por dos razones. En primer lugar, el gobierno central abolió el tributo indígena independizándose de este modo de los ingresos generados en los Andes. En segundo lugar, la burguesía limeña que surgió a raíz de la exportación del guano, buscaba estabilizar la vida política nacional puesto que los frecuentes pronunciamientos y guerras civiles ponían en peligro sus inversiones, sea en las plantaciones de azúcar y algodón, sea en los bancos.

Sin embargo, en ningún momento el gobierno central llegó a tener suficiente poder para implantar en alguna provincia una reforma que afectara a los intereses de la elite de dicha provincia. De ahí que el gobierno central nunca impusiera programa político alguno a nivel provincial sino que más bien dejase actuar a los notables de provincia. Por otro lado, para conquistar el poder político a nivel nacional era imprescindible estar aliado con la burguesía limeña. Con el auge del guano desapareció la preponderancia política del campo y los grupos limeños - que ya no eran los mismos de antaño- volvieron a jugar un rol dominante en el espacio político peruano, ahora llamado nacional. Pero la dominación a nivel nacional no se basaba exclusivamente en la fuerza propia de la burguesía sino más bien en la cooptación de una buena parte de las elites rurales. 
Desde los años veinte se debate la cuestión si la burguesía limeña era una burguesía nacional. Mientras unos lo niegan, subrayando que estaba vinculada estrechamente a capital y mercados extranjeros, otros lo afirman sosteniendo que sí existía un proyecto político nacional. ${ }^{71}$ Por los argumentos expuestos en este artículo queda bien claro que la burguesía limeña logró imponer una paz política desconocida y controlar las instituciones centrales del Estado nacional. Sin embargo, no cambió las relaciones sociales prevalecientes y tampoco amplió la participación política de una manera significativa. Entonces la burguesía era nacional en el sentido que tenía un impacto importante en la política nacional, pero no era nacional en el sentido de que intentara crear una nación de ciudadanos con igualdad de derechos o extender la esfera del poder estatal hasta el distrito más apartado del territorio nacional.

La Guerra con Chile acabó con la estabilidad política recién establecida. Tanto la derrota contra el vecino sureño como las guerras internas destruyeron gran parte del capital de la burguesía limeña. Por más de quince años, el Perú volvió a sufrir las sangrientas luchas internas conocidas desde la independencia. Recién en la llamada República Aristocrática (1895-1919), se encontraron nuevamente mecanismos políticos para apaciguar las luchas entre las diferentes elites. ${ }^{72}$ Esta paz política se basó, como en los años setenta, tanto en el fortalecimiento del poder central (uniéndose viejos protagonistas antagónicos) como en la cooptación de elites provinciales. Es decir, políticamente los años setenta se parecían a la época situada entre 1895 y 1919 por el hecho de que se logró estabilizar el país sin ampliar la participación política. El Perú seguía siendo una república de notables lo cual era un progreso importante en comparación con la posindependencia. Pero considerando los retos sociales y económicos de principios del siglo XX, se trató de un modelo bastante atrasado.

71 Mariátegui, José Carlos: Siete ensayos de interpretación de la realidad peruana, Lima (47. a ed.), 1986, págs. 20-24; Bonilla: Guano y burguesía; McEvoy, Carmen: Un proyecto nacional en el siglo XIX. Manuel Pardo y su visión del Perú, Lima, 1994; Gootenberg: Imagining Development, págs. 58-129.

72 Acerca de esta época, véase Basadre: Historia de la república, ts. 11 y 12; Burga, Manuel y Flores Galindo, Alberto: Apogeo y crisis de la República Aristocrática, Lima, s.f.; Miller, Rory: "The Coastal Elite and Peruvian Politics", Journal of Latin American Studies, 14, 1 (Cambridge, 1982), págs. 97-120. 